\title{
Haver, Charlotte E., Von Salzburg nach Amerika. Mobilität und Kultur einer Gruppe religiöser Emigranten im 18. Jahrhundert
}

\section{Patrick Farges}

\section{(2) OpenEdition \\ Journals}

Édition électronique

URL : http://journals.openedition.org/ifha/6499

DOI : $10.4000 /$ ifha.6499

ISSN : 2198-8943

Éditeur

IFRA - Institut franco-allemand (sciences historiques et sociales)

Référence électronique

Patrick Farges, « Haver, Charlotte E., Von Salzburg nach Amerika. Mobilität und Kultur einer Gruppe religiöser Emigranten im 18. Jahrhundert », Revue de l'IFHA [En ligne], Date de recension, mis en ligne le 01 janvier 2012, consulté le 22 septembre 2020. URL : http://journals.openedition.org/ifha/6499 ; DOI : https://doi.org/10.4000/ifha.6499

Ce document a été généré automatiquement le 22 septembre 2020.

(C)IFHA 


\title{
Haver, Charlotte E., Von Salzburg nach Amerika. Mobilität und Kultur einer Gruppe religiöser Emigranten im 18. Jahrhundert
}

\author{
Patrick Farges
}

En 1731-32, environ 22000 " protestants salzbourgeois » sont contraints à l'émigration : selon Ch.E.H., il s'agit là davantage d'un point culminant de l'imposition du pouvoir absolutiste en Autriche que d'une question religieuse. Dès lors, le destin des « Salzbourgeois » passionne toute l'Europe protestante, qui soutient financièrement leur émigration. C'est en particulier les piétistes de Halle qui vont maintenir des liens avec les Salzbourgeois. En 1734, les premiers Salzbourgeois accostent sur le sol américain, dans la colonie de Géorgie nouvellement créée : ils y fondent la ville d'Ebenezer près de Savannah. Les transports transatlantiques se suivent $(1734,1735$ puis 1741), tandis que d'autres Salzbourgeois sont accueillis par la Prusse ou les Pays-Bas. L'ouvrage nous plonge dans l'histoire longue de cette expérience migratoire. La volumineuse étude de Ch.E.H. est la publication de sa thèse d'habilitation, qui repose sur une imposante collection de sources manuscrites et publiées (journaux, correspondances, rapports, imprimés, récits migratoires) conservées à Salzbourg, Munich, Augsbourg, Halle, Münster et Berlin. L'étude couvre plusieurs champs historiques, notamment l'histoire régionale, l'histoire religieuse, l'histoire des migrations et l'histoire de la colonisation américaine.

2 La première partie de l'ouvrage reconstitue la tradition du " crypto-protestantisme » des régions montagneuses autour de Salzbourg (Pongau, Pinzgau, Lungau). Dans ces régions alpines reculées, une pratique d'un luthéranisme « de la première heure "s'est transmise oralement de génération en génération, peu affectée par les évolutions religieuses ultérieures et créant des phénomènes d'insularité (qui furent d'ailleurs réactivés dans le contexte migratoire). Par ailleurs, les habitants de ces régions, 
habitués à une mobilité régionale transalpine, étaient, selon l'auteure, mieux préparés que d'autres à une grande migration.

3 La seconde partie présente la réalité religieuse en Géorgie, où se côtoient anglicans, presbytériens, méthodistes, luthériens et quelques juifs. Les catholiques sont exclus. D'abord colonie idéale au projet philanthropique, la Géorgie s'aligne bien vite sur le fonctionnement des colonies voisines dont l'économie repose sur les plantations et l'esclavage. Les journaux des Salzbourgeois permettent de retracer les âpres débats autour de la question de l'esclavage, des relations avec les « Indiens » ou du partage des parcelles.

4 La troisième partie de l'ouvrage est consacrée aux récits de la rencontre de l'« autre ». La société coloniale s'organise en effet par cercles concentriques, selon une hiérarchie des altérités : autres personnes parlant l'allemand (Suisses, Saxons, Souabes), autres Européens (Anglais, Écossais), Indiens, Noirs ... La division se fait également en fonction de l'appartenance religieuse : anglicans, réformés, luthériens ... Dès les années 1770, le clivage recouvre le projet d'indépendance des colonies américaines : on distingue alors les «Anglais " (partisans de la couronne britannique) et les "Américains » (parmi lesquels une majorité des descendants des premiers Salzbourgeois).

5 Les quatrième et cinquième parties, passionnantes, sont consacrées à l'analyse des traces d'une acculturation, tant spirituelle (religion, valeurs, savoirs) que matérielle, des Salzbourgeois et de leurs descendants sur plusieurs générations.

6 Patrick Farges (université Sorbonne Nouvelle - Paris III) 